\title{
Research on the Utilization Mechanism of High-end Innovative Talents in China
}

\author{
Li Ge \\ Deputy General Manager, Beijing Timehr Management Consulting Co., Ltd., Beijing, China \\ Email address: \\ elainegeli@hotmail.com \\ To cite this article: \\ Li Ge. Research on the Utilization Mechanism of High-end Innovative Talents in China. Humanities and Social Sciences. \\ Vol. 8, No. 1, 2020, pp. 20-24. doi: 10.11648/j.hss.20200801.13
}

Received: November 26, 2019; Accepted: February 4, 2020; Published: February 25, 2020

\begin{abstract}
In recent years, the process of economic globalization and information globalization has been speeding up, which has brought unique development opportunities to China. However, talents, especially high-end talents, play an increasingly important role in social development. Therefore, to achieve sustainable development and enhance innovation ability, we must strengthen the cultivation and utilization of high-end innovative talents, and provide talent guarantee for transformation and development. First of all, this paper analyzes the current situation of the utilization mechanism of high-end innovative talents in China, and points out that there are some problems in the utilization mechanism of high-end innovative talents in China, such as the traditional thinking constraining the development of talent mechanism, the large loopholes in talent management system, the lack of implementation of talent incentive mechanism, and the overall strength of talent training mechanism Weak, lack of talent security and development mechanism, etc., and elaborated the background and reasons of the problem, and then put forward effective suggestions and measures. Starting from the management mechanism, incentive mechanism, security mechanism, development mechanism, training mechanism and other aspects, this paper puts forward specific improvement measures for the current problems in the utilization of high-end innovative talents in China, which has important practical significance.
\end{abstract}

Keywords: High-end Innovative Talents, Utilization Mechanism, Incentive Mechanism, Security Mechanism

\section{Introduction}

In recent years, China has continuously increased the construction of high-end innovative talent utilization mechanism, and formed new measures in talent introduction, incentive, management and other aspects. Many scholars have also carried out in-depth research and exploration in this regard. Gao xiuye believes that under the background of the era of "mass entrepreneurship, mass innovation", the connotation of innovative talents should be redefined, the extension of innovative talents should be broadened, so as to reconstruct the system of innovative talents, and then the cultivation system of innovative talents of different types and levels can be constructed based on the functional differentiation of higher education From concept to practice, from practice to realization [1]. Shi Changhui, fan Lihong, etc. based on the theory of national innovation system, with the producers, diffusers and users of knowledge as the main analysis dimensions, combined with the ecosystem theory in ecology, constructed the structure of China's science and technology innovation talents ecosystem, clarified the basic principles and evolution mechanism of the system operation, and analyzed the evolution process and faced problems of China's science and technology innovation talents ecosystem Finally, the paper puts forward some policy suggestions to promote the sustainable development and high-quality output of the system [2]. Through in-depth analysis of the internal relationship between the integration of science and education and the cultivation of innovative talents in application-oriented universities, Fang Hongjun et al. Discussed the internal and external adjustment and control modes of the integration of science and education to cultivate innovative talents, and provided important reference for the development of the cultivation of innovative talents under the integration of science and education in Colleges and universities in China [3]. Through comparative study, Du Caiping pointed out that in recent ten years, there are some problems in the domestic academic research in this field, such as the convergence of views, the lack of sufficient evidence support, the lack of systematic, hierarchical and 
structural research, the traditional and backward research methods, and the lack of theoretical research, which can not effectively guide the cultivation and practice of Applied Innovative Talents in Colleges and universities [4]. From the perspective of innovation ecosystem, Shi Wei and Qian Si put forward countermeasures and suggestions on the growth environment of innovative talents from three levels: macro, meso and micro, and put forward future research prospects from three aspects: focusing on specific industries and talents, subdividing the characteristics of development stages and interdisciplinary integration [5]. In fact, there are some problems in the utilization mechanism of high-end innovative talents in most regions of China. The total amount of high-end innovative talents is low, and there are also some problems in the talent structure, which has a serious impact on the local economic development and restricts the overall development of the country.

\section{Status of High-end Innovative Talents Utilization Mechanism}

\subsection{Development of Talent Mechanism Is Constrained by Traditional Thinking}

The traditional talent utilization mechanism has been continued for many years in China. As a result, the concept of outdated talent utilization mechanism is still maintained in many regions, which cannot be changed in a short period of time, resulting in all along existed wrong tendency in high-end innovative talent utilization mechanism. In most areas, the utilization of high-end innovative talents does not received knowledge enough, and the importance of intellectual capital is not realized [6]. As a result, the talent utilization mechanism has not received the attention it deserves. Under such a tendency, China's stable development is affected to some extent, causing outflow of some outstanding high-end innovative talents.

\subsection{There Are Big Loopholes in the Talent Management System}

At present, there is no well-established high-end innovative talent management system in many parts of the country, causing that large-scale difficulties are in front of such talents in their development process. In severe situations, it will lead to the lag of urban development. Although many regions in China have recognized the importance of high-end innovative talents for urban development, and realized that the talent management system is irreplaceable in such talent utilization mechanisms, in fact, the talent management system is still not improved in most regions, and the management system still has big problems. In particular, systematic system design is lacked in introduction, training, and incentives of high-end innovative talents, which makes the high-end innovative talents in cities of the country not stable enough [7]. The talent management system established in some regions is not perfect, resulting in that the talent management mechanism is not reasonable enough.

\subsection{Talent Incentive Mechanism Is Not Fully Implemented}

The incentive mechanism is the core of the talent utilization mechanism. If the talent incentive mechanism is not implemented, then the enthusiasm of high-end innovative talents cannot be mobilized. Taking the high-end innovative talent incentive mechanism in Hebei Province as an example, the province's incentive policy is similar to those in other provinces, which, mainly based on assisting policies for high-end innovative talents, provides convenient and diverse preferential policies in fiscal and taxation incentives for entrepreneurs of such talents. However, the incentive mechanism in this part is not perfect, as is shown that there are no clear incentives for achievement identification and performance reward of high-end innovative talents and the incentive mechanism such as the results distribution policy is still to be improved. In addition to Hebei Province, the above problems exist in many other regions of China [8]. In terms of the high-end innovative talent incentive mechanism, all regions in China must fully demonstrate local characteristics on it. At present, the talent incentive mechanisms in regions are limited to basic materials such as innovation and entrepreneurship. The lack of innovation and specialization in the talent incentive mechanism has seriously hindered the introduction of high-end innovative talents in China.

\subsection{The Overall Strength on Talent Training Mechanism Is Not Strong Enough}

Employer must have a long-term vision in talent training, but from the current development situation, some cities lack long-term strategic development vision, exemplified by the fact that the mechanism for learning and training of high-end innovative talents lacks, which leads to the inability to effectively improve the training, finally imposing an irreversible impact on the sustainable development of the city and the country. In particular, in some cities, the technology industry is the mainstay [9]. If the high-end innovative talents cannot be trained, knowledge will not be updated in a timely manner, and capabilities not continue to be improved. Some cities, due to poorly developed scale and low development funds, cannot provide good training for high-end innovative talents. This situation, however, will create a vicious circle only, constituting quite adverse impact on the development of cities and country.

\subsection{Lack of Talent Security and Development Mechanism}

In addition to the above aspects, in the actual investigation process, it's found that many cities lack a talent security mechanism and a talent development mechanism. Under such circumstances, the cities could not retain high-end innovative talents. Most high-end innovative talents keep clear plans for their own development, and have certain requirements for the cities' security mechanism. Urged by this, if the cities lack talent security and development mechanism, it will not only 
cause loss of talent resources, but also serious outflow of talents, imposing terrible impact on the development of the cities. For example, according to the incomplete statistics of a certain department, the outflow of talents in the technology industry in Guangzhou exceeded 50\% in 2017 alone. Not only that, talent security and development mechanism nowadays in most areas are limited to project support and life security, thus are less attractive to high-end innovative talents, from which employer could learned that the talent utilization mechanism needs to be fundamentally improved. In addition, certain problems still exist in business services, medical insurance, cultural life, education quality, etc., so there are still some difficulties for high-end innovative talents to solve their children's schooling, information acquisition, family medical treatment, etc. [10].

\section{Research on the Countermeasures for the Utilization Mechanism of High-end Innovative Talents}

Urged by the vision to solve this problem fundamentally, this paper starts from the reality and conducts comprehensive research on management mechanism, incentive mechanism, security mechanism, development mechanism and training mechanism, so that the utilization mechanism of high-end innovative talents can be fundamentally improved, so as to lay a good talent foundation for national development.

\subsection{Establishing a Scientific Talent Management Mechanism}

The management mechanism constitutes the basis of the talent utilization mechanism and, the key task of cities at this stage is to transform the awareness of talent utilization, and to create favorable conditions for talent management. For example, in the process of managing high-end innovative talents in Japan, the knowledge application ability of talents is put more focus, and a lifelong employment system for talents is adopted, so that talents and enterprises can form a community with a shared future and interest. From the perspective of Japan's high-end innovative talent management mechanism, China should strengthen its publicity on the people-oriented management model and management awareness, and guide enterprises to establish a good corporate culture. Not only that, Japan keeps positive in pioneering business in overseas markets. In learning from the Japanese development model, in addition to theoretical innovation, China also needs to establish a modern management concept from the government level and the enterprise level, and to employ scientific talent management mechanism to attract talents and retains talents, thus laying a good foundation for the overall development of cities and country. Taking Hebei Province as an example, looking at the talent development situation in Hebei Province in recent years, the strongest growth trend was the in 2014. In view of the adopted talent management system, employer could find that many characteristic industrial parks were established in that year, attracting a large number of companies and talents. Therefore, in the new era, Hebei Province should, combining the actual situation of regional development, clarify its own functional orientation, actively establish cooperative relationships with surrounding cities, and further develop innovative and entrepreneurial parks, scientific research institutions, and innovation bases for better management on talents.

\subsection{Establishing Perfect Talent Incentive Mechanism}

A perfect incentive mechanism plays an important role in ensuring the rational development of the talent utilization mechanism. If employer consider the management mechanism as the basis of the utilization mechanism, then the incentive mechanism serves its core soul. First of all, local governments should appropriately increase the incentive funds for high-end innovative talents. In the reward systems of developed countries such as the United States and Japan, innovation reward account for the largest proportion. Therefore, local governments can cooperate with social organizations and scientific research groups to establish a diversified investment mechanism oriented to key development fields in local areas [11]. Taking Shanxi Province as an example, the province has established a research incentive fund, and encourages social capital and enterprises to be involved in it, thus forming a diversified research investment mechanism to reduce government's fund pressure. Secondly, local governments should appropriately increase preference in fiscal and taxation. All countries in the world have adopted fiscal and taxation preferential policies in the utilization of talents, from which all areas in China may refer to some successful experience in their development progress. For instance, based on the key development fields in local areas, enterprises that contribute to the development of key fields can be subject to a corporate income tax rate of down to $15 \%$. Finally, the local government can establish a system of share and share option incentives system. At present, there are fewer successful experiences in this area in China and more in foreign countries. This is a reform for high-end innovative talents training departments such as state-owned high-tech enterprises, colleges and universities, and innovative talents practice bases, which, through share and share option incentive system, grant different share and share option rewards such as technology invested as capital stock and dividend right to talents who have achieved important results [12]. For example, many companies in Japan adopt the method of employee stock ownership to make employees actively involved in the innovation and development of enterprises, and this incentive system has a long valid time with a strong binding effect.

\subsection{Establishing a Sound Talent Guarantee Mechanism}

In addition to the above aspects, the talent security mechanism is also of great importance. In the new era, the country should also establish a talent service system oriented to market and a technology service system targeted on with 
results transformation, so as to transform the traditional high-end innovative talent utilization mechanism into a utilization mechanism that is in line with market development to improve the service quality and optimize the service system. First, a diversified talent service model should be established, and the governments, enterprises, and society should cooperate to promote diversified development of talent services. For example, Guangzhou has established an association in talent service industry working with a number of world-class headhunting companies and global human resources companies. Secondly, it is necessary to establish a big data platform and a service center, and form a talent contact station and a talent database for resources share among government departments, universities, research institutions, and enterprises. Finally, a comfortable service guarantee system must be established. For example, Beijing provides medical care for high-end innovative talents, and the local governments can also implement special services for talents to ensure that talents can be introduced, retained, and scientifically utilized [13].

\subsection{Establishing a Correct Talent Development Mechanism}

In the process of investigating the brain drain of the country and local areas, it was found that this phenomenon is mainly caused by the fact that talents feel that there is no room for development, thus leaving the enterprise and even the city. In order to avoid this problem, it is necessary to establish a correct talent development mechanism in the process of practical application. High-end innovative talents concerned the development space most. If the local government is free from good talent development mechanism, it will suffer from serious brain drain. The growth environment varies from each individual talent, and their development road is diverse as well, which tells that a perfect talent development system is a necessary condition to ensure their development [14]. Therefore, a correct talent development mechanism must be established and formed in the country and localities to create a good development environment and development space and let high-end innovative talents feel their own value and their own responsibility. By this means, they can give full play to their own capabilities and make positive contributions to national and local development in the process of actual work. For example: The country and the localities can establish and form a fault-tolerant mechanism for innovation and, form an innovative environment with certain tolerance to let talents carry out innovative activities and try to explore under less press, give talents the opportunity to fully demonstrate their talents, and fully stimulate their potential, thus ensuring their excellent achievements for local development.

\subsection{Establishing a Strict Staff Training Mechanism}

I In addition to the above aspects, the training mechanism is also a part non-negligible in the talent utilization mechanism because talent training needs to be conducted from talent development requirements and according to actual needs. It is necessary to establish a talent training plan that is in line with urban development, which is supposed to start from both long-term and short-term to ensure the rational implementation of talent training. At the same time, an effective feedback mechanism should be established to investigate the effectiveness of the training work and to resolve the problems in the training process under multi-dimensional testing. Not only that, a strict examination mechanism should be established to conduct scientific assessment to the implementation of training work. In such a manner, training work of relevant personnel can be monitored, and the talent training mechanism can be fully developed [15].

\section{Conclusion}

All in all, it can be learned that high-end innovative talents are one of the important factors to ensure the healthy development of the country. The continuous development of the country's social economy has placed the problem of talent shortage in a ever-growing serious position. At present, there are certain problems in the utilization of high-end innovative talents in most parts of the country. It has been proved by practice that the comprehensive development of the country and the cities cannot be separated from the optimization of the talent utilization mechanism and the implementation of a sound management mechanism, incentive mechanism, security mechanism, development mechanism and training mechanism.

\section{References}

[1] Xiuye Gao. From elitism to Populism: the discourse practice turn of innovative talent training $[\mathrm{J}]$. Contemporary education science, 2019 (10): 18-21.

[2] Changhui Shi, Lihong Fan, Guangxi He. Evolution, problems and Countermeasures of China's science and technology innovation talent ecosystem [J]. Science and technology guide, 2019, 37 (10): 66-73.

[3] Hongjun Fang, Xiujing Guo. Research on the relationship between the integration of science and education and the cultivation of innovative talents in Applied Universities [J]. Economist, 2019 (03): 169-170.

[4] Caiping Du. A review of the research on the cultivation of Applied Innovative Talents in China in the past decade [J]. Journal of higher education, 2018 (22): 32-34.

[5] Wei Shi, Si Qian. Current situation and future of research on growth environment of innovative talents [J]. Modern management science, 2018 (07): 93-95.

[6] Linlin Liu. Research on the law and path of the growth of innovative talents [J]. Scientific management research, 2014, 32 (01): 82-85.

[7] Xingfeng Liu. Research on the promotion mechanism of knowledge appreciation of innovative talents [J]. Scientific management research, 2014, 32 (02): 82-85. 
[8] Wensong Sun, Qiming Tang, Ruting Dong. The impact of knowledge spillover on innovation performance of local high-tech enterprises in China -- Based on the perspective of international innovative talent flow [J]. Technology and economy, 2012, 31 (12): 7-12.

[9] Junhua Chen, Xin Li. Main characteristics of innovative talents and design of training environment $[\mathrm{J}]$. Scientific management research, 2013, 31 (04): 101-104.

[10] Yong Zhou, Hairong Cui, Yingying Xu, Research on the Development Environment for Urban Innovative Talents with International Competitiveness [J]. Jiangsu Silk, 2018 (04): 4-6.

[11] Lihua Peng, Dong Luo, Shuxian Li, Junmei Chen, Zhaoyi Yuan, Analysis on the Innovative Talents Management Mechanism and Improvement Strategy of in Sci-Tech Cities [J]. Science and Technology Management Research 2018, 38 (15): 189-193.

[12] Jing Zhang, Research on the Development Strategy of Innovative Talents in Guangzhou [D]. Lanzhou University, 2016.

[13] Ying Huang, Thoughts and Suggestions on Anshan City's Attraction to High-end Innovative Talents [J]. Journal of Anshan Normal University, 2018, 20 (03): 44-47. [1] Ren Yang, Chen an. On innovative talents and their behavioral characteristics [J]. Education research, 2017, 38 (01): 149-153.

[14] Xueyan Li. Growth characteristics of innovative talents and collaborative training management mechanism [J]. Southeast academic, 2017 (03): 88-93.

[15] Shitian Guo. Research on the development of innovative talents in contemporary China [D]. Shandong University, 2012. 